\title{
News and Views
}

\section{International Silica Cycle Workshop held in Hangzhou}

TRÉGUER Paul ${ }^{1,2 *}$, RAN Lihua ${ }^{3 *}$, CHAI Fei ${ }^{1}$, CHEN Jianfang ${ }^{3,1}$

${ }^{1}$ State Key Laboratory of Satellite Ocean Environment Dynamics (SOED), Hangzhou 310012, China

${ }^{2}$ European Institute for Marine Studies IUEM (University of Brest, UBO), Rue Dumont D'Urville, Plouzané 29280,

France

${ }^{3}$ Laboratory of Marine Ecosystem and Biogeochemistry (LMEB), Ministry of Natural Resource, Hangzhou 310012,

China

Received 20 November 2018; accepted 10 December 2018

(C) Chinese Society for Oceanography and Springer-Verlag GmbH Germany, part of Springer Nature 2018

Silicon is the second most abundant element on the planet Earth. Its electronic configuration is close to that of carbon, but the aqueous environment prevailing on our planet gives advantages to carbon compounds at the expenses of siliceous compounds. Silicified organisms, however, are everywhere on Earth, particularly in the marine realm where siliceous diatoms play a key role in the ocean biological carbon pump. Thus, a better understanding of the processes that control the silica cycle at global scale is crucial.

On 23-24 October 2018, an international silica cycle workshop was held for the first time in China in line with international initiatives of marine silica cycle researches. It was organized and hosted by the Second Institute of Oceanography, the Ministry of Natural Resource (SIO/MNR), in Hangzhou, China. About 50 scientists from 11 different institutes/universities of China and other countries were invited to attend.

During the workshop, recent advances of different aspects on silica cycle, including the updated budget of global marine silica cycle, silica cycle in polar oceans, Pacific Ocean, Indian Ocean, Chinese seas and major rivers, the role of marine silicifiers in silica cycle, molecular biology of marine diatoms, diatoms in a changing environment, etc. were discussed. Involvement of Chinese institutes/universities in the international "Silica School", and organizing the SILICAMICS 3 Conference in 2021 in China were also discussed.

Foundation item: The Foundation of Distinguished Visiting “Ocean Star" Scholar, State Key Laboratory of Satellite Ocean Environment Dynamics (SOED). 